\title{
PAISAJE, ESCLAVITUD Y MEDIO AMBIENTE EN LA ECONOMÍA CAFETALERA BRASILEÑA: VALE DO PARAIBA, SIGLO XIX
}

\author{
Rafael Marquese \\ Universidade de São Paulo \\ marquese@usp.br
}

Recibido: 7 octubre 2014; Aceptado: 1 febrero 2015.

Cómo citar este artículo/Citation: Marquese, Rafael (2015), “Paisaje, esclavitud y medio ambiente en la economía cafetalera brasileña: Vale do Paraiba, Siglo XIX", Asclepio 67 (1): p078. doi: http://dx.doi.org/10.3989/asclepio.2015.04

RESUMEN: El artículo analiza las estrategias de administración del paisaje y del trabajo adoptadas en las plantaciones esclavistas del Valle de Paraíba a lo largo del siglo XIX. Sostiene que la presencia masiva de la población africana esclavizada, en un contexto local y global muy turbulento, marcado por la competencia entre los diferentes productores mundiales para el control de este artículo y por la intensificación de la resistencia esclava, condujo a la adopción, por los propietarios esclavistas, de las formas de administración del paisaje en sus haciendas que buscaron restringir la autonomía de los esclavos en el proceso de trabajo y, al mismo tiempo, explotar al máximo su capacidad de trabajo. El resultado de estas formas de administración del paisaje y del trabajo fue un proceso de devastación ambiental sin precedentes. En el momento de la crisis de la esclavitud en la década de 1880, estos patrones históricos se volvieron contra los propios esclavistas, que sin embargo lograron mantener el dominio sobre la tierra por medio de una reconfiguración específica de las formas de explotación agraria.

PALABRAS CLAVE: Agricultura; Esclavitud; Brasil Imperio.

\section{LANDSCAPE, SLAVERY AND ENVIRONMENT IN THE BRAZILIAN COFFEE ECONOMY: VALE DO PARAIBA, XIXTH. CENTURY}

ABSTRACT: The article analyses the landscape and labor management devices adopted in the nineteenth-century Paraiba Valley slave coffee plantations. It argues that the presence of an enormous mass of enslaved Africans in a turbulent local and global conjuncture framed by world competition between different coffee producers and increasing slave resistance led planters to adopt measures of landscape management that closely restricted slave autonomy in the labor process as they tried to extract the maxim amount of labor from the slaves. The outcome of these forms of landscape and labor management was a process of unprecedented environmental devastation. At the time of slavery crisis in the 1880s, these historical patterns turned against slaveholders, who however managed to maintain dominion over the land by means of a specific reconfiguration of the forms of agronomic exploitation.

KEY WORDS: Agriculture; Slavery; Brazilian Empire.

Copyright: () 2015 CSIC. Este es un artículo de acceso abierto distribuido bajo los términos de la licencia Creative Commons Attribution-Non Commercial (by-nc) Spain 3.0. 


\section{INTRODUCCIÓN}

En enero de 1822, de regreso a la ciudad imperial de Río de Janeiro después de explorar en varios viajes científicos las zonas del sur y centro-sur de Brasil, el naturalista francés Auguste de Saint-Hilaire había señalado que parte de su colección recogida en las provincias de Río de Janeiro y Minas Gerais se había echado a perder. Aburrido, pero resignado, decidió emprender su último viaje antes de regresar a Francia. Así, entre enero y mayo de 1822 , volvió a cruzar los caminos de herradura que atraviesan la Serra do Mar, el valle del río Paraíba del Sur y la Serra da Mantiqueira en dirección al sur de Minas Gerais, teniendo la oportunidad de viajar por el Caminho do Comércio, abierto hacia unos años con el objetivo de articular la entonces sede del imperio portugués con la zona de producción de alimentos en las tierras altas de Mantiqueira.

Aparte de las idas y venidas de los muleteros y los parajes en el camino, otros dos puntos merecen el registro del naturalista, ya malhumorado. El 2 de febrero, después de ganar los primeros contrafuertes de la Serra do Mar, escribió: "el terreno sigue siendo montañoso y cubierto de bosques vírgenes". Al día siguiente, a orillas del río Paraíba: "nada extraordinario en el camino. La tierra sigue siendo montañosa y cubierta de selva virgen". Cuatro de febrero, después de cruzar el río: "siempre montañoso y boscoso". Día cinco, cerca de la futura ciudad de Valença, "continuó las montañas y los bosques. Poco antes de llegar al pueblo se puede ver desde lo alto del pico de la montaña vasta extensión de tierra, observando todas las montañas lados cubiertos de bosques". Entre este punto y la aduana del rio Preto, en la frontera con Minas Gerais, 6 de febrero: "para llegar al río Petro, donde se cruza es montañoso y cubierto de tierra bosque virgen, y cuando en alguna cresta alta se puede ver gran extensión de tierras, sólo se notan los bosques y las montañas." (Saint Hilaire, 1974, pp. 20-24).

Sesenta años más tarde, cubriendo la misma región en la dirección este-oeste, ahora en cómodos vagones de ferrocarril y no en los lomos de mulas, el agrónomo C.F. van Delden Laërne vio un paisaje completamente diferente. Nacido en Batavia, Java, con amplia experiencia agronómica del terreno en la posesión holandesa de las Indias Orientales, Laërne visitó entre los meses de septiembre de 1883 y abril de 1884 las regiones de café de las provincias de Río de Janeiro, Minas Gerais y São Paulo. De regreso a Holanda, escribió lo que se considera como una de las principales fuentes para la historia global de la economía cafetalera, al comparar sistemáticamente el coloso brasileño con las otras zonas productoras del artículo, Java en particular. Su relato fue inmediatamente traducido al inglés y francés, y contenía un bonito mapa sobre las dos grandes zonas cafetaleras de Brasil (ver figura 1).

Figura 1. Mapa: C.F. van Delden Laërne, Brazil and Java. Report on Coffee-Culture in America, Asia, and Africa. Londres-Haia: Martinus Nijhoff, 1885.

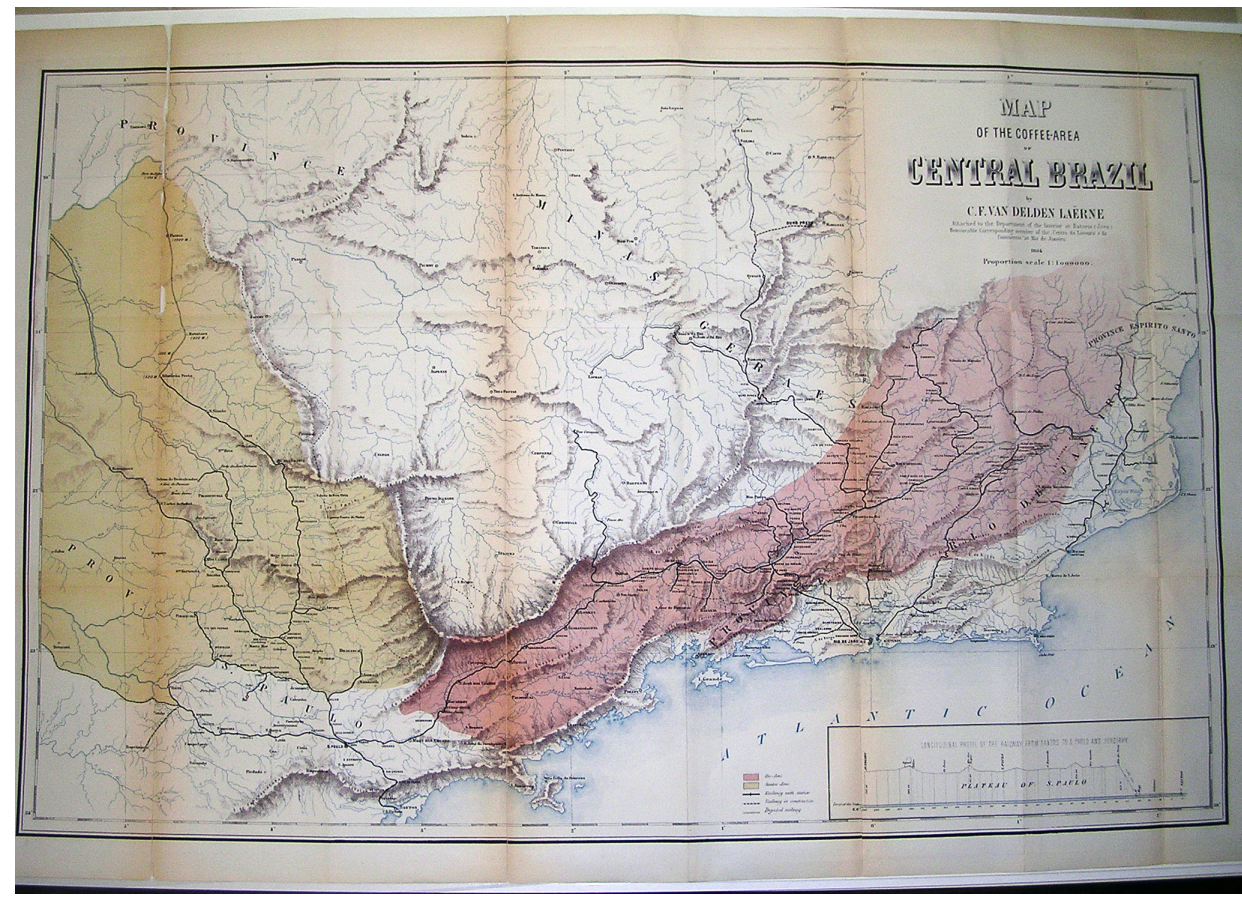


En amarillo, la "Zona de Santos", esto es, el Oeste de la Provincia de São Paulo; en rojo, "la Zona del Rio" (el puerto de Rio de Janeiro ha sido anotado con la cruce), esto es, el Valle de Paraíba. Las líneas en negro indican la red de ferrocarriles.

Tal como en la narrativa de Saint-Hilarie, la monotonía siguió para establecer el tono del relato de Laërne, pero en otro diapasón. "La parte del valle de Paraíba", escribió él,

que abarca los distritos de Barra Mansa, Piraí, Vassouras, Valencia y Paraíba do Sul, en Brasil es considerado ya que se ha agotado la mitad. Un viaje a través de esta región es la cosa más triste que puedo imaginar en un país tropical. Por mucho tiempo, el tren pasa por colinas desnudas, guarnecidas por gigantescos vassourais cenizas, reliquias deplorables de las plantaciones de café una vez tan espléndidas que se puede decir que produjeron oro, (Laërne, 1885, pp. 282-283).

La última frase proporciona la clave para comprender lo que sucedió en la región. Cuando Saint-Hilaire lo cruzó en 1822, el café brasileño empezaba el arranque que pronto iba a situar a Brasil como el mayor productor de este artículo en el mercado mundial. El valle del Paraíba do Sul, o simplemente Vale do Río Paraíba, con tierras en las fronteras de las provincias de Sao Paulo, Río de Janeiro y Minas Gerais, ha sufrido un cambio completo en el transcurso de dos generaciones: relativamente desocupado en 1800 , cincuenta años después adquiriría el carácter de una típica zona de plantación esclavista, movilizando grandes cantidades de trabajadores cautivos para explotar sus recursos naturales.

De hecho, el proceso de ocupación del valle de Paraíba mantuvo estrecha relación con la trata transatlántica de esclavos. El enorme volumen del tráfico entre 1811 y 1830, cuando desembarcaron en los puertos del centro-sur de Brasil Imperio aproximadamente 560.000 africanos esclavizados, suministró la fuerza de trabajo original para las primeras plantaciones de café del valle (Florentino, 1995, p. 59; véanse, también los números actualizados en www.slavevoyages. org). En los tres años siguientes a la aprobación de la ley de 7 de noviembre de 1831, el tráfico -ahora ilegal- fue residual, dado que el decreto fue leído por los contemporáneos como una medida que iba ser efectivamente cumplida. La práctica sistemática de la trata, equivalente a las cifras de 1820 , se reanudó sólo después de 1835, en gran parte como resultado de las acciones de los terratenientes esclavistas y sus representantes políticos en el Parlamento Imperial, quie- nes comenzaron a exigir en los espacios de discusión pública la anulación de la ley de 1831 (Mattos, 1987; Parron, 2011; Youssef, 2010). Entre 1835 y 1850, en la medida en que fueran desembarcados en el centrosur de Brasil aproximadamente 546.000 africanos esclavizados ilegalmente, se expandían las grandes haciendas de café en el Valle. Esas grandes propiedades cafetaleras, con más de un centenar de cautivos cada una, fueran las responsables del grueso de la producción brasileña a lo largo del siglo XIX (Salles, 2008; Marquese \& Tomich, 2009).

Cuando se terminó definitivamente la trata transatlántica de esclavos, la demografía de las principales ciudades y villas del Valle de Paraíba Medio, el corazón de la economía cafetalera brasileña, demostró la estrecha correlación entre una actividad y otra. Basándose en los informes de los presidentes de la provincia de Río de Janeiro, Robert Slenes (2000, p. 214) estimó que, en el municipio de Vassouras en 1850, "el $72 \%$ de los esclavos, el $60 \%$ del total de los negros y morenos y un $49 \%$ de toda la población eran africanos". Estos datos han sido corroborados por estudios que cuantifican la presencia de esclavos africanos en las testamentarías de Vassouras, Paraíba do Sul y Bananal. Sus autores indican claramente la presencia de una típica demografía de plantaciones esclavistas, es decir, la concentración de esclavos en grandes unidades con amplio predominio masculino y la fuerza de trabajo compuesta de mano de obra en edad productiva óptima (Gomes, 2006, pp. 163-78; Salles, 2008; Moreno, 2013; Fragoso, 2013).

Dicha información plantea el problema del papel de la esclavitud en la conformación del paisaje cafetero del Valle del Paraíba. Además del hecho evidente de que fueron los brazos de los africanos y sus descendientes los que habían derrumbado los bosques, plantados los arbustos, cosechados los cultivos, beneficiaron y construyeron las imponentes casas de vivienda monumentales de las haciendas cafetaleras de los propietarios, algunas de las cuales siguen en pie, la cuestión se refiere a un punto que ha llamado la atención de los especialistas en la última década, a saber, la agencia africana en la configuración del paisaje del Nuevo Mundo.

Una de las obras más importantes en este campo es sin duda la de la geógrafa Judith Carney. Mediante el estudio de la implantación de la cultura del arroz en las Américas, especialmente en las tierras bajas de Carolina del Sur, Carney intentó demostrar cómo el conocimiento desarrollado originalmente en la costa de África Occidental y trasplantado en los bu- 
ques negreros por los propios africanos esclavizados fue decisivo para el éxito de la actividad en el Nuevo Mundo (Carney, 2001). Basándose en este punto, que no obstante ha sido criticado y debatido Eltis, Morgan \& Richardson, (2007), véase también el fórum de $A H R$ Exchange (2010), Carney propuso con el también geógrafo Robert Voeks, un amplio programa de investigación para examinar las marcas de la diáspora africana en el paisaje brasileño, sobre todo el legado de los africanos en el manejo de los "recursos alimenticios para la subsistencia, a la supervivencia, la resistencia y la identidad propia" (Carney y Voeks, 2003, pp. 141). Estos dos geógrafos recuerdan, además del caso del arroz, una gran variedad de plantas y alimentos con significados medicinales y religiosos, ambientadas con éxito en Brasil por los esclavos africanos y sus descendientes. Por fin, en un libro más reciente escrito con Richard Nicholas Rosomoff, Carney amplió su perspectiva original para comprender el conjunto de legados africanos en el paisaje agrario de las Américas (Carney \& Rosomoff, 2009).

La interpretación que quizás puede servir para el arroz y otras plantas, sin embargo, no lo sirve para el café, un arbusto igualmente originario del continente africano. El plan propuesto por Carney y sus colegas puede conducir a la reificación de los productos agrícolas que los africanos trajeron de su continente, si el contenido específico de las relaciones sociales que se estructuran a partir de la explotación de estos productos en el paisaje no se examina adecuadamente.

Es importante que, por un lado, operemos con una comprensión sustantiva de paisaje, que sea capaz de evitar los problemas que contienen tanto el tratamiento puramente morfológico de la escuela Carl Sauer, como los de la revisión culturalista defendida por Denis Cosgrove. La tarea, por lo tanto, es investigar las relaciones concretas entre la producción material del paisaje y sus esquemas de representación visual, lo que necesariamente requiere que analicemos de forma integrada las estrategias de gestión del mundo natural y la gestión del trabajo. Concibiéndose el paisaje como morfología, como ambiente construido y como representación, se posibilita examinar cómo el paisaje ha estructurado las relaciones laborales y, al revés, cómo las relaciones de trabajo estructuran el paisaje (Mitchell, 1996, pp. 1-35). Por otro lado, esta perspectiva sustantiva del paisaje también nos permite evitar un límite relativamente común del campo de la historia ambiental, es decir, el tratamiento de la naturaleza y de la sociedad como entidades binarias ontológicamente apartadas (Moore, 2011, pp. 1-2).
La región de Valle de Paraíba durante el siglo XIX se caracterizó por la presencia abrumadora de la esclavitud negra. La organización del proceso de trabajo esclavo en sus plantaciones de café implicaba vectores específicos de transformación del paisaje; con el tiempo, un medio ambiente significativamente alterado por la devastación ambiental (debido a las estrategias señoriales de la gestión del paisaje y de la mano de obra) modificó las condiciones históricamente dadas a la reproducción de las relaciones sociales esclavistas. Este artículo busca captar este doble movimiento en dos momentos diferentes, y por eso, se divide en dos partes. El argumento principal es que la presencia masiva de esclavos africanos en el Valle de Paraíba, en un contexto local y global bien turbulento, marcado por la competencia entre diferentes productores globales por el control de este artículo y por la intensificación de la resistencia esclava en el plano local, llevó a la adopción, por los hacendados esclavistas, de formas de administración de los paisajes de sus propiedades que intentaban restringir brutalmente la autonomía de los cautivos en el proceso de trabajo y, al mismo tiempo, explotar al máximo su capacidad de trabajo. El resultado de estas formas de administración del paisaje y del trabajo fue un proceso de devastación ambiental sin precedentes. En el momento de crisis de la esclavitud en la década de 1880, estos patrones históricos se volvieron contra los propios dueños de esclavos, que sin embargo lograrían mantener el dominio sobre la tierra por medio de una reconfiguración específica de las formas de explotación agraria.

\section{I.}

A pesar de lo que su nombre podría indicar, la especie arabica del cafeto es originaria de las zonas montañosas de bosques de Etiopía. A principios del siglo $\mathrm{XVI}$, los mercaderes musulmanes estimularon con éxito la aclimatación de la planta en el extremo sur de la Península Árabe, que empezó a ser cultivada intensivamente por los agricultores del Yemen. Hasta finales del siglo XVII, la producción y la comercialización del producto se mantuvo en régimen de monopolio musulmán (Tuchscherer, 2003). Las familias campesinas intentaron reproducir las condiciones originales del cafeto: la siembra se produjo en la sombra de grandes árboles; en el manejo de la planta, los cafetos ni eran restringidos en su altura (lo que iba a llamarse "contención" en Cuba) ni eran podados, alcanzando alturas promedio de entre 4 y 6 metros; durante la cosecha, se extendían colchonetas debajo de los pies y los árboles eran sacudidos, por lo que sólo se desprendían los frutos maduros; el proceso de secado 
se daba en las propias esteras utilizadas en la recogida de los frutos, ahora expuestas al sol; finalmente, la separación de la pulpa y del grano del pergamino se realizaba en molinos de piedra (Maria Rodrigo \& Boloix, 1817, pp. 165-168; Caldeira, 1843, pp. 10-11; Tuchscherer, 2003, p. 54).

Como se puede ver, en tal modelo la producción era necesariamente restringida. Cuando los holandeses y los franceses tomaron posesión de la comercialización de la planta, con el fin de abastecer la creciente demanda metropolitana, buscarían adaptar el cultivo a una gran escala, con una organización de trabajo muy diferente de los patrones campesinos del Yemen. Esto ocurrió todavía en el espacio del Océano Índico, antes de que la producción cafetalera se cruzara para el Atlántico (Campbell, 2003, p. 69). JeanLouis Dulac Alléon, al publicar su Mélange d'Histoire Naturelle en 1754, registró que en la isla de Bourbon (hoy Reunión), los cafetos eran plantados en línea y contenidos cuando llegaban a la altura de un hombre adulto. Las razones fueron dictadas por el uso de mano de obra esclava: la contención facilitaba la cosecha, "debido a que sus ramas más altas son del tamaño de los esclavos", mientras que la plantación en hileras paralelas, además de dejar "muy agradable y vistosa la perspectiva de la finca", facultaba a su amo "ver fácilmente la labor de todos sus esclavos" (Alléon-Dulac, 1800, pp. 128, 138).

Dicho manejo - la siembra en líneas con contención de los arbustos- estuvo presente en todas las áreas esclavistas del Atlántico que produjeron café a gran escala en el siglo XVIII, es decir, Martinica, Suriname, Jamaica y en particular Saint-Domingue. Después de la década de 1790, a raíz del vacío creado por la revolución de los esclavos en esta última colonia y el aumento de la demanda en las zonas centrales de la economía mundial, aparecieron en el mercado mundial nuevas zonas productoras del artículo, como Cuba y Brasil. Las técnicas desarrolladas por los poderes coloniales holandeses, británicos y francesas fueron difundidas en la América portuguesa, a través de las traducciones, desde los primeros años del siglo XIX, destacando la notable colección O Fazendeiro do Brazil, publicado en once volúmenes entre 1798 y 1806 por el fray José Mariano da Conceição Veloso (Marquese, 1999, pp. 121-131). En uno de los volúmenes relacionados con el café, Veloso publicó el tratado de P.-J. Laborie, productor esclavista de café de SaintDomingue que se refugió en Jamaica y que, apenas dos años antes, había publicado la primera edición de su libro en inglés (Laborie, 1800). Al largo del si- glo XIX, el manual de Laborie fue considerado como la más importante publicación agronómica sobre el tema (Marquese, 2009).

Aunque sea difícil documentar la transmisión de las técnicas mediante el examen de la recepción de las publicaciones contemporáneas, se puede afirmar que la combinación siembra en líneas / contención de los cafetos fue adoptada en Brasil tan pronto despegó la industria del café a gran escala. En la medida en que, en la década de 1820, eran fomentadas las grandes haciendas cafetaleras en el Valle de Paraíba, se acopló, al aprendizaje progresivo de las técnicas agrícolas, la construcción de un conocimiento local. El movimiento puede ser rastreado por medio de las publicaciones agronómicas. Hasta 1835, los escritos sobre el café publicados en Brasil solamente propagaron las técnicas de las Antillas, la mayoría de las veces sacándolas de $O$ Fazendeiro do Brazil, pero sin referirse específicamente a la producción en rápido proceso de crecimiento en el Valle de Paraíba. Los únicos autores que escribieron directamente sobre la producción brasileña entre los años 1820 y 1830 fueron algunos viajeros extranjeros que estuvieron en las provincias de Río de Janeiro, São Paulo y Minas Gerais (Marquese, 1999, pp. 157-167).

En 1836, sin embargo, salió a la luz el primer trabajo escrito en base a la experiencia acumulada en la producción de café en Brasil. Su autor, el padre José Joaquim Ferreira de Aguiar, entonces con 31 años de edad, había vivido durante cinco años en la gran hacienda cafetalera Desengaño Feliz, en Valença, Rio de Janeiro, observando cuidadosamente las técnicas desarrolladas localmente. Su objetivo, para traerlas al público, fue precisamente indicar su distinción en relación a las técnicas del Caribe.

El Valle de Paraíba presentaba condiciones ambientales ideales para el cultivo del café. En realidad, la región así llamada compone una cuenca entre las laderas de Sierra de Mantiqueira al norte, y la Sierra do Mar, al sur (altitudes variables entre 1600-800 metros sobre el nivel del mar; las coordenadas básicas son

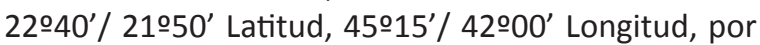
tanto, al sur de la zona intertropical de América del Sur). Los afluentes del río Paraíba (río Negro, río Pirai etc) corren en rieles diagonales al plato principal de la cuenca, entre pequeños contrafuertes que también reciben en los topónimos locales el nombre de sierras. La topografía del Valle de Paraíba se caracteriza por los llamados mares de morros, pequeñas elevaciones redondeadas - de ahí el nombre de "medias-naranjas" - formadas por los procesos de acción morfo 
climáticos intensos en sus tierras de origen granítico, basáltica y gnássicas muy antiguas (Ab'Sáber, 2003, pp. 45-64). En estos suelos pobres se ha formado la gruesa cubierta de la Mata Atlántica, un vasto bosque tropical que cubría a principios del siglo XVI casi toda la costa norte-sur de Brasil, abarcando la mayor parte de las actuales provincias de Espírito Santo, Río de Janeiro, Minas Gerais y São Paulo. La calidad del suelo poco contribuyó para la constitución de la Mata Atlántica. Por el contrario, fue la cobertura de vegetación que había formado el suelo en la cuenca del río Paraíba do Sul. La continua caída de las hojas bajo la densa sombra de la copa de los árboles, y seguidamente mineralizadas por insectos, hongos y bacterias, dio origen al humus tan valorado por los agricultores. Como bien explica Warren Dean (1996, p. 27), "el bosque creció y se extendió sobre un sustrato orgánico generado por él mismo."

Las demandas específicas de la especie arabica del cafeto en términos de precipitaciones (1300-1800 $\mathrm{mm} / \mathrm{año}$ ), de temperatura media anual ( 20 a 24 으) y de tierra (el suelo no podría ser seco o húmedo), se cumplieron en la topografía de los mares de colinas cubierta por la Mata Atlántica (Dean, 1996, p. 195), algo que así fue bien observado por el Padre José Joaquim Ferreira de Aguiar a principios de los años de 1830. La práctica local por él anotada demostró que los suelos adecuados para el cultivo de café eran los existentes en las colinas de medias-naranjas, típicas del paisaje del Valle y cubiertas de bosques vírgenes; las plantaciones de café en las tierras bajas, aunque frondosos, rindieron pocos frutos. La preparación del terreno se daba por la tala y quema de los bosques, lo que no implicaba un gasto excesivo de tiempo de trabajo y posibilitaba el crecimiento vigoroso de árboles de café. La plantación seguía líneas verticales desde la parte superior de la colina hasta su base, distantes unas de las otras de catorce a dieciséis palmos ( $3 \mathrm{~m}$ a 3,5 m), dependiendo de la calidad de la tierra; en los tres primeros años de la plantación de los árboles, el amplio espacio entre las hileras era aprovechado para el cultivo de maíz, frijol y yuca, con el doble objetivo de garantizar sombra a los pies recién sembrados y mantener a los esclavos trabajando productivamente en la labranza de comestibles. En el manejo, el cafeto era contenido cuando alcazaba la altura de diez pies $(2,2 \mathrm{~m})$ para facilitar la recolección de frutos y evitar romper las ramas en la operación de la extracción; el deshierbe, a su vez, se realizaba tres veces al año. Como el rendimiento decreciente de los cafetos viejos, con más de dos décadas, no compensaba el coste de manejo, a cada año había que recurrir a la plan- tación de nuevos cafetales, a una tasa de $10 \%$ de los árboles existentes en la finca (Aguiar, 1836, pp. 6-11).

Una rápida comparación con el manual de Laborie sirve para entender acerca de lo que estas técnicas se habían apartado de la norma del Caribe. En el SaintDomingue pre-revolución, era una práctica común que los agricultores plantasen los arbustos en quincunces, "cuya ventaja es para unirse a las filas, y por lo tanto ganar terreno" (Laborie, 1800, p. 159). El espaciamiento patrón transmitido por Laborie (1800, p. 162) de dos metros cuadrados por quincunce significaba unas 15.700 matas por alqueire (unidad de área empleada en Brasil, equivalente a $48.400 \mathrm{~m}^{2}$ ). Si leemos la tabulación preparada por Laërne (1885, p. 276; véase también Muniz, 1979, p. 25), es posible notar que, en la distancia mínima señalada por Aguiar, había cerca de 5.100 matas por alqueire.

¿Cuál fue la lógica de esta aparente pérdida de la tierra en el Vale do Paraíba? En primer lugar, hubo una relación directa con la cantidad de tierra virgen disponible en Brasil, sin términos de comparación con la oferta relativamente escasa de este insumo en las islas caribeñas. El punto central, sin embargo, se refiere a la organización del proceso de trabajo. La alineación vertical de los arboles, con amplio espacio entre las hileras, obedeció a la regla de la visualización como un medio de control de los trabajadores, algo que ya se había adoptado desde el Índico, pero que adquirió un nuevo significado en las haciendas en el Valle. En la zafra o en el deshierbe, cada esclavo se asignaba en una fila de arbustos, comenzando a trabajar en las cimas de las colinas hasta llegar a su base: el mayoral o capataz en la parte inferior tendría el control visual total sobre las actividades, observando (en el caso del deshierbe) si la línea de esclavos seguía el mismo ritmo dictado por los trabajadores de las puntas, o (en el caso de la recogidas) si se cosechaban todos los árboles o si les dañaban (Aguiar, 1836, p. 12).

Las plantaciones cafetaleras de Brasil combinaban así las dos formas básicas de organización del proceso de trabajo esclavo presentes en otras regiones de la plantación del Nuevo Mundo: las cuadrillas bajo mando unificado y el sistema de tareas individualizadas ("gang system" y "task system", conforme los términos del análisis de Morgan, 1988). Sin embargo, el sistema de tareas adoptada en el Valle de Paraíba se apartó significativamente del empleado en las unidades de café del Caribe. Laborie, teniendo en cuenta la práctica local en Saint Domingue, documentó que se requería de los esclavos en los años de buena cosecha la recoja de una tarea determinada, dejando al cauti- 
vo el disfrute del tiempo libre después de su cumplimiento (Laborie, 1800, pp. 216-217). Aguiar, a su vez, compuso su manual en el momento exacto en que los agricultores de Brasil innovaban en esta área:

cada trabajador así puede cosechar por día tres a tres y medio, y hasta cuatro alqueires en años de abundancia [RM - alqueire, aquí, es una medida de volumen, y no de área]; las mujeres generalmente son más diestras en este servicio. Algunos agricultores tienden a conformarse con tres alqueires, dejando a retirarse del trabajo si se presenta en cualquier momento; sin embargo, otros hacendados pagan más de esa tarea, si el trabajador se mantiene a cosechar todos los frutos hasta el final: mucho conviene que los mayorales deben tener cuidados de no permitir que se coseche la fruta aún no madura, porque no pueden hacer un buen café; ni tampoco que se desfolien o que se rompan las ramas al coste de la futura cosecha. Algunos agricultores, sin embargo, para que no se den segunda carrera a los cafetales, pronto cosechan todos los frutos incluso los aún poco maduros, y afirman que, siguiendo el procedimiento en los secaderos con los bien maduros, no hay diferencia apreciable al final entre unos y otros; lo que, por tanto, es digno de tomar ventaja, (Aguiar, 1836, pp. 12-13).

Es posible leer en esta cita tres modos distintos de la organización del trabajo en los procedimientos de cosecha. En los dos primeros casos, la tarea a ser cumplida por el esclavo se fijó en tres alqueires, con una estricta supervisión del mayoral para evitar la recolección de los frutos no maduros. La diferencia entre los dos estaba en la forma de estimular al trabajador esclavizado, asignándole tiempo libre si el esclavo había cumplido la tarea (sistema corriente en las Indias Occidentales), o con una recompensa monetaria en caso de que recogiera la cuantía mínima exigida. En el tercer método, lo que importaba al hacendado esclavista era antes la cantidad que la calidad de la fruta, con la máxima economía de trabajo: con la cosecha de frutos verdes y maduros, era evidente que la cuantía recogida para cada esclavo en años de buena zafra sería considerablemente mayor que los tres alqueires usuales.

Documentos posteriores dan cuenta de que el tercer procedimiento se convirtió en la norma en el Valle de Paraíba. Véase, por ejemplo, el caso del más famoso manual agronómico de la región, escrito por el poderoso señor de esclavos Francisco Peixoto de Lacerda Werneck, el Barón Pati do Alferes, publicado originalmente en 1847 en las páginas del Auxiliador da Industria Nacional, reunido en un libro en este mismo año y reimpreso con adiciones en dos ocasiones después de la muerte del autor, en 1863 y 1878:
La cosecha varía de acuerdo con su abundancia; si es desigual, un recogedor no puede a veces tomar dos que uno a tres alqueires; pero si él hace todo madura, entonces la tarea debe pasar de cinco, seis y siete fanegas alqueires. A horas de medida a la puesta del sol, el administrador debe estar presente con el fin de castigar a los que no dieran a la tarea, que debe gradarse al estado del café y las fuerzas del individuo. Uno de los mejores expedientes que yo he impuesto en principio, cuando mis esclavos no sabían recoger el café, y que yo he tomado muy buen resultado, fueron los premios; por ejemplo, marcaba cinco alqueires como una tarea, diciéndoles que el que lo superaba tendría por cada cuarta 40 réis de gratificación; con este engaño que se observó fácilmente, yo obtuve de los esclavos siete alqueires, que más tarde se estableció como regla general, (Werneck, 1985, p. 67).

Las variaciones bienales en los rendimientos de los cafetales eran muy comunes en el Valle de Paraíba, como siempre ocurría cuando los árboles se plantaban sin sombreado (Matiello, 1991, pp. 18-19). De todos modos, se destaca el hecho de que la tarea mínima en un buen año sea significativamente superior que el registro de diez años antes por Aguiar. También se subraya la mensuración individual de las tareas, establecidas por el administrador con base en su evaluación sobre el volumen de la cosecha; aunque la cosecha se llevaba a cabo en cuadrillas, el castigo o la recompensa se aplican individualmente a cada trabajador. Por último, en un pasaje en el que la arrogancia señorial se manifiesta sin rodeos, se observa que el incentivo para el incremento de la recolección más allá de la cuantía mínima sería en dinero.

Hay múltiples registros de la segunda mitad del siglo XIX que demuestran la extensión de la práctica de pagar dinero en efectivo como incentivo para que los esclavos cosechasen por encima del mínimo fijado por los administradores (Stein, 1990, p. 207; Marcondes de Moura, 2002, p. 162; “Instruções gerais", 2000, p. 109; Guimarães, 2009, p. 37). En julio de 1854, al hablar en el Senado Imperial de Brasil sobre el origen de su fortuna, Honório Hermeto Carneiro Leão (el futuro marqués de Paraná) aclaró a sus colegas que su origen estaba en la explotación "racional" de sus esclavos, es decir, en la imposición de una pesada carga de trabajo: "si yo hice cosecha tan abundante, no es porque he empleado a gran número de brazos; hay hacendados que tienen el doble y aún más, y sin embargo, obtienen menos. No tengo en la hacienda [de Lordello, en el actual municipio de Sapucaia, Rio de Janeiro] de más de 150 esclavos entre grandes y pequeños; pocos empleados libres; pago a mis esclavos lo que cosechan 
en los días de guarda, y el exceso de sus respectivas tareas en los días de servicio." (Carneiro Leão, 1957, p. 281). Treinta años después, Laërne escribió que en el Valle de Paraíba el estipendio monetario se adoptó para "fomentar el esclavo que cosechó más. Como regla, él gana 200 réis por alqueire para los primeros cuatro o cinco semanas de la temporada, suma que se eleva a 240 réis por alqueire en el resto de la cosecha." (Laërne, 1885, p. 301). Cuando la zafra era abundante, la cosecha se extendía a los domingos, y, por lo tanto, el trabajo de los esclavos se debía remunerar.

¿Por qué los hacendados brasileños se encontraron con la necesidad de estimular a sus esclavos con ganancias monetarias en caso de trabajo excesivo? Aparte de los esfuerzos de los cautivos para ampliar sus márgenes de autonomía en relación con sus amos, a través del ejercicio de una economía propia que abarcaba no sólo a sus cultivos sino que también todos los ingresos extras que quizás podrían amasar, debemos recordar las particularidades del proceso de producción del café. La cosecha (recogida y procesamiento) era el cuello de botella de la actividad, el punto que determinaba el tamaño ideal de la fuerza de trabajo en la hacienda (Gorender, 1985, p. 214). Laborie (1800, p. 49) fue claro en ese sentido al escribir que el productor cafetalero "que se establece debe calcular cuidadosamente y sólo extender los brazos a la proporción de cultivos que puede tener".

Los caficultores del Vale de Paraíba, sin embargo, transfirieron esta ecuación al límite. Por un lado, el esquema de administración del paisaje que ellos adoptaron (plantación alineada verticalmente con amplio espacio entre las hileras), facilitó la estricta supervisión de los grupos de esclavos que trabajaban al unísono, en el deshierbe y la cosecha; por otro lado, la adopción en la cosecha de un método de gestión que combinaba el trabajo colectivo, la recogida indiscriminada de los frutos y la mensuración individual les facultó la imposición de elevadas tajas de trabajo a los cautivos. En Saint-Domingue, se le asignaba a un esclavo de campo generalmente entre 1.000 y 1.500 matas de café, lo mismo que se imputaba a los esclavos jamaicanos (Geggus, 1993, p. 77; Higman, 2001, pp. 159-191). En Cuba, el estimado era que un esclavo de campo cultivaba un promedio de 2.000 matas, número similar al inicio de la producción de café en Brasil (Noda, 1830, pp. 131-133; Taunay, 2001, p. 130). En los años 1830 y 1840, con la especialización progresiva de las explotaciones en el Vale do Paraíba, el importe asignado a los traba- jadores esclavizados aumentó sustancialmente. El diplomático suizo Johann Jacob von Tschudi, al visitar la zona de Cantagalo, Rio de Janeiro, en 1860, pudo consultar el libro de notas de un hacendado con datos desde mediados del siglo. Nos interesan aquí los datos para el período 1847-1850, cuando salió en el mercado editorial de Brasil el manual de Lacerda Werneck. Tschudi constató que, en aquella finca, cada cautivo de campo cultivaba 3.934 matas de café, una cantidad sorprendente a la vista de los padrones antillanos anteriores (Tschudi, 1980, p. 41). No es de extrañar, pues, que en los años de cosecha abundante (en aquella hacienda de Cantagalo, la productividad media era de64@ por mil matas de café, mientras que el Caribe la productividad no era de más que 30@ por mil matas), hacendados y administradores adoptasen una serie de incentivos para dar cuenta de la cosecha y el procesamiento, entre los que se destacó el pago por recoja extra y trabajo los domingos.

Esta tasa de explotación del trabajo esclavo fue sin duda uno de los factores que impulsarían el café brasileño y le garantizarían el dominio absoluto en el mercado mundial del producto de la década de 1830 en adelante (Marquese y Tomich, 2009). En respuesta a un marco económico internacional competitivo, que requería constante aumento de la productividad para mantenerse en él, pero también frente a una mayoría demográfica de esclavos africanos jóvenes refractarios al comando señorial, los propietarios del Valle de Paraíba adoptaron estrategias de la organización del proceso de trabajo con el objetivo de aumentar su grado de control sobre los esclavos, haciéndoles trabajar cada vez más, pero con pequeñas oportunidades para el usufructo de una economía propia. Tal fue la lógica subyacente de un patrón de administración del paisaje que implicaba tan grande pérdida de los recursos naturales.

La aprehensión simbólica de este modelo por los señores esclavistas se puede observar en una famosa pintura parietal de fazenda Resgate (ver figura 2), ubicada en Bananal, São Paulo, compuesta en la segunda mitad de la década de 1850 por José María Villaronga. Empleando un dispositivo que se encontraba en los orígenes renacentistas de la pintura de paisaje, el pintor catalán abrió la "ventana" del comedor de la casa de vivienda para observar las líneas verticales de las plantaciones de café perfectamente simétricas y distanciadas, cuyo producto fluyó como la forma natural, sin la necesidad del trabajo humano, en las arcas de su propietario (Marquese, 2010). 
Figura 2. Pintura parietal en trompe-l'oeil del comedor de la hacienda Resgate, Bananal, São Paulo, c.1860; fotografía de Reinaldo Funes Monzote, noviembre de 2005.

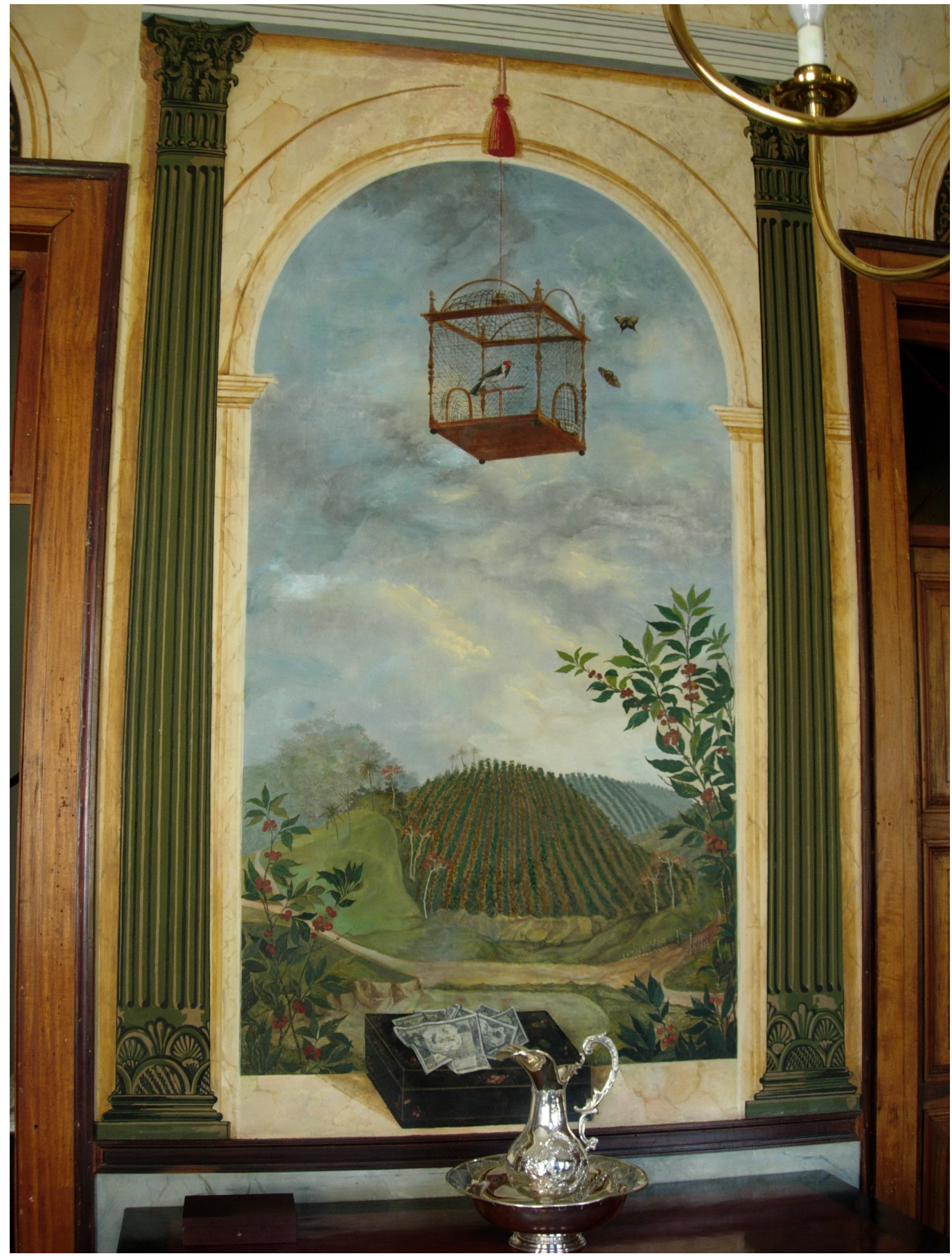

Los esclavos pueden haber desaparecido de la pintura de Villaronga, pero estaban allí, trabajando en las plantaciones de café de Manoel de Aguiar Vallim, dueño de la Resgate. Trabajando, enriqueciendo a los demás propietarios del Valle de Paraíba y resistiendo. El historiador norteamericano Stanley Stein, basado en entrevistas realizadas en la década de 1940 con los antiguos esclavos para su libro sobre Vassouras, ha descrito en páginas admirables lo cotidiano del trabajo diario en el campo, siempre 
impulsado por el cántico de los jongos. Las cuadrillas de esclavos trabajaban entre las hileras de café bajo la supervisión constante y amenazadora de los mayorales, "pero si la vigilancia se aflojaba, los trabajadores aprovechaban la oportunidad para moderar la actividad mientras que los hombres y mujeres encendían sus pipas o se recostaban en sus azadas para momentáneamente limpiar el sudor" (Stein, 1990, p. 200; véase también Slenes, 2000, p. 218).

La burla de los esclavos era algo bien conocida para los propietarios, así como los esfuerzos de ellos para tomar el control del proceso de trabajo. Esos esfuerzos a menudo tomaban a los mayorales y capataces como cómplices, que así trataban de aliviar tensiones inherentes a su función. Los hijos de Antonio Clemente Pinto (Barón de Nova Friburgo), asumiendo la fabulosa herencia de su padre que murió en 1869, compuesta por quince haciendas y más de dos mil esclavos en las villas de Cantagalo, St. Fidelis y Nova Friburgo (Rio de Janeiro), prepararon un documento muy detallado para estandarizar la administración de las diversas unidades cafetaleras de la familia. Semejante en el contenido de las prescripciones a los manuales agrícolas coetáneos, el escrito firmado en febrero de 1870 era no obstante más detallado cuando se trataba de los enfrentamientos con los esclavos. En cuanto a la cosecha, por ejemplo, el documento declaraba que la tarea iba a ser establecida por el administrador de cada una de las haciendas al término de la jornada de trabajo, dictando a cada uno de los esclavos durante la inspección llevada a cabo en el patio de los secaderos antes que ellos fuesen encerrados en los barracones; al día siguiente, el propio administrador iba a inspeccionar las cestas recogidas individualmente para verificar si la tarea se había cumplido. El objetivo de la prescripción era, sobre todo, la calidad de la autoridad en el campo: en los términos de la normativa, "debe desterrarse la idea de que el mayoral poco tiene que hacer en la cosecha por esta hacerse a la tarea, pues del contrario el dueño de la hacienda nunca más necesitará de la autoridad del mayoral” (“Intruções gerais", 2000, p. 110).

La acomodación entre mayorales y esclavos derivaba, en parte, de la práctica de distribución de los esclavos de campo en cuadrillas (en portugués, ternos). En las grandes unidades de café del Valle de Paraíba, con equipos de esclavos de campo con más de 50 individuos, la cadena de comando se componía generalmente del administrador general de la hacienda, de los mayorales de secaderos y de campo, y de los capataces (en portugués, feitores de roça), los últimos por lo general reclutados entre los propios esclavos. Laërne, que observó cuidadosamente las propiedades de los hermanos Clemente Pinto en el área de Cantagalo, escribió que cada capataz era responsable por el control de ternos compuestos por 20 a 25 esclavos, hombres y mujeres; cada grupo tenía un(a) cocinero(a) esclavo(a), que preparaba las comidas en los cafetales; cuando trabajaban juntos, los diferentes ternos eran supervisados directamente por el administrador (Laërne, 1885, p. 293).

Forzado por sus patrones para extraer mucho esfuerzo de los esclavos, los capataces y encargados no obstante tuvieron que negociar con ellos todos los días en los trabajos en los cafetales (Machado, 1987, p. 68; García, 2004, p. 241). Hay un caso de especial relevancia a los objetivos de este artículo. El 17 de octubre de 1866, el mayoral portugués Manoel Duarte Simões fue asesinado en la hacienda del comendador Venancio José Gomes da Costa, en la parroquia de la Sagrada Familia de Tinguá, Vassouras. Esa era, sin duda, una propiedad muy problemática. Su dueño fue, en distintas ocasiones, presidente del cabildo de Baependi, en el sur de Minas Gerais; en octubre de 1866, él no estuvo de Vassouras. Simões fue contratado apenas dos semanas antes de su asesinato, en plena fase final de la cosecha de café, para reemplazar el mayoral Francisco Bernardes da Costa, que sin embargo continuó residiendo en las tierras de la hacienda. A lo largo de las investigaciones del proceso criminal, algunos de los esclavos dijeron que Francisco Bernardes había sido despedido por pasar por alto el hecho de que cautivos de la hacienda estaban robando café para cambiarlo por ron y tabaco con Jerônimo Siqueira de Vasconcelos, otro antiguo mayoral de la propiedad antes de su adquisición por el comendador Venâncio, y que también permaneció como residente en sus tierras, con una pequeña venta. Francisco Bernardes, sin embargo, expuso una explicación distinta. En sus palabras, él había renunciado al cargo "porque no podía soportar los esclavos y tolerar sus excesos." "Cuando mayoral de la hacienda del comentador Venancio", continuó, "a menudo caminando por los campos, yo encontraba café oculto y botellas de aguardiente (...), en los propios barracones los negros se emborracharon; la astucia de ellos era tal en las noches los esclavos sacaban las tablas del suelo de los barracones y así salieron a comprar aguardiente y vender el café que robaron". Su juicio sobre el asunto era perentorio: "todos los esclavos son generalmente mal educados, desobedientes y rebeldes de cumplir con sus obligaciones." ${ }^{11}$ 
De todos modos, fuese Francisco Bernardes despedido por su patrón o renunciado al puesto por libre voluntad, el contraste entre su modelo de orden y el de Manoel Duarte Simões aparece en casi todos los testimonios de los esclavos. Según Barbara Maria da Conceição, que realizaba el trabajo doméstico en la casa de Jerônimo Siqueira, "a los esclavos no les gustaba Simões, porque no les perdonaba, y estaba siempre encima de ellos, gustando los esclavos más de Francisco Bernardes, a quien estaban acostumbrados pues no los castigaba, los dejaba en el campo y se iba a dormir y los negros hicieron lo mismo." El relato más significativo para este análisis, sin embargo, se encuentra en otro punto. Duarte Simões, al asumir el cargo de mayoral, no sólo prohibió - usando el látigo - los contactos de los esclavos con Jerônimo Siqueira, sino que también trató de imponer una nueva urgencia al ritmo de trabajo para la cosecha de café en su fase final. La tarea pactada entre los esclavos y el antiguo mayoral Francisco Bernades fue de três alqueires. Duarte Simões empezó requiriendo que los esclavos "dieran tarea de cuatro alqueires y los que no lo dan serían castigados" (testimonio del esclavo Adão). El día antes de su asesinato, Duarte Simões mandó clavar un poste de castigo en el terrero delantero de los cafetales en recoja, indicando claramente lo que pretendía hacer con los cautivos que no cumplían con las nuevas reglas de trabajo.

Este episodio demuestra (en la figura de Francisco Bernardes) la camaradería o la acomodación que podían surgir en los contactos cotidianos entre los mayorales de las plantaciones y los esclavos, pero también indica (en la figura de Duarte Simões) las tensiones involucradas en los esfuerzos para aumentar la producción de café. En resumen, la asombrosa proporción de matas de café por esclavo de campo impuesta por los hacendados esclavistas del Valle de Paraíba, tuvo que enfrentar la dura oposición de sus cautivos que, con las armas disponibles, resistieron como pudieron a la demanda de trabajo de sus amos.

\section{II.}

La correlación social de fuerzas en el Valle de Paraíba era sin embargo profundamente asimétrica: la proporción plantas de café / esclavos expresaba exactamente ese cuadro social, significando que los señores de esclavos promovían, en un sólo movimiento, el agotamiento de los recursos naturales y humanos al servicio de la acumulación de capital. De hecho, a pesar de todas las acciones de la resistencia esclava, los métodos de gestión del trabajo y el paisaje agrícola allí empleados constantemente reafirmaban el poder señorial. En la estrategia de destrucción "controlada" de los recursos forestales, los cafetos plantados en alineación vertical se mantenían productivos para un máximo de 25 años, pero sus rendimientos disminuyeron notablemente a partir de 15 años. Para mantener los niveles estables de producción, fue necesario plantar constantemente cafetos en los bosques talados, con el fin de sustituir los arbustos viejos e improductivos a punto de ser convertidos en pastizales (Fragoso, 1983; Laërne, 1885, pp. 253-382). Este esquema agronómico devastador, adoptado conscientemente por los propietarios de las haciendas, que combinada la continua expansión de los desmontes, el plantío vertical alineado con el amplio espacio entre las hileras de café, el trabajo colectivo en el deshierbe y el sistema de tareas en la cosecha para compensar la falta de mano de obra, se prolongó hasta bien entrada la década de los ochenta, en el contexto de la crisis terminal de la esclavitud en Brasil.

En sus últimas dos décadas, en la medida que la esclavos envejecían, la tierra virgen escaseaba y disminuía la productividad de las plantas, la carga de trabajo aumentó considerablemente para los trabajadores esclavizados. En su visita al Valle del Paraíba entre 1883 y 1884, Laërne quedó impresionado con el increíble ritmo de destrucción de los bosques, el agotamiento de los suelos en las zonas de más antigua actividad cafetalera, y sobre todo con las tasas de explotación del trabajo. Laërne (1885, pp. 294-295) estimaba que entre doce y quince años, la pérdida de la cobertura del suelo con las Iluvias, debido a la plantación alineada verticalmente en las colinas de media naranja, era de 20 a $35 \mathrm{~cm}$, es decir, un tercio de la capa media de humus existente después de la tala y quema de bosques vírgenes; no fue un accidente, por lo tanto, que la producción y el valor de mercado de las plantaciones de café se desplomaran después de esta edad. Después de tres décadas, la cobertura de los suelos originalmente cultivados con cafetales desapareció por completo. $\mathrm{Y}$, con ella, la propia posibilidad de mantenerse la actividad cafetalera esclavista en el tiempo.

Con el aumento de los precios del café en los años 1870, la plantación de nuevos cafetales se aceleró, incluso en las zonas antiguas con menor disponibilidad de tierras vírgenes. Antes, es decir, en los años 1850 y 1860 , se atribuyó a un esclavo de campo en el Valle 
de Paraíba un máximo de 4.500 a 5.000 matas; luego, en 1883:

la pasión por la plantación [de café] ha sido tan violenta que en la mayoría de los distritos de la zona de Río, un esclavo tiene que hacerse cargo de más de 7.000 matas, (Laërne, 1885, p. 290).

En sus entrevistas con hacendados y administradores, el agrónomo holandés observó que un esclavo era capaz de coger el pico de la cosecha de ocho a nueve alqueires de café, es decir, el triple de la tarea anotada por el padre Aguiar en la década de 1830 y lo que se consideraba como la norma por los esclavos del comendador Venancio en la acción violenta contra el mayoral Manoel Duarte Simões en 1866. El historiador Robert Slenes (1986, pp. 139-140), citando esas mismas palabras de Laërne, avanzó la hipótesis de que, en zonas del Valle con pocos recursos forestales, los hacendados que no habían optado, en los años setenta, a emigrar a las fronteras cafetaleras del Oeste de São Paulo, la Zona da Mata de Minas Gerais o el Sur de Espírito Santo, adoptaron la estrategia de "incrementar la velocidad con la que consumían sus tierras y plantaciones."

En el Valle de Paraíba del siglo XIX, las posibilidades materiales de que los africanos en la diáspora y sus descendientes recreasen conocimientos agrícolas traídos de África fueron muy restringidas. En el paisaje de la producción cafetalera, la agencia africana, tal como fue concebida por Judith Carney, pocas posibilidades tenían de prosperar. El problema, sin embargo, permanece abierto con respecto a la economía y cultivos propios de los esclavos. Con base en los conocimientos históricos disponibles, es posible decir que no hubo aporte africano sustantivo en esa esfera, en el sentido indicado por la geógrafa. Hay evidencia consistente de que los productos de elección para los esclavos para cultivar en sus conucos y jardines fueron los que eran elegibles para la venta en el mercado, es decir, el café y el maíz, exactamente los productos que sus amos les obligaban a cultivar durante la semana (Silva, 1984, p. 157; Ribas, 1989, pp. 187-193; Santos, 2014).

Pero también es posible afirmar que, en sus cultivos propios, la organización del trabajo siguió una lógica muy diferente que la impuesta por los propietarios de lunes a sábado. Los historiadores han documentado muy bien la oposición de los esclavos al trabajo en cuadrillas bajo estricta vigilancia. Más importante es el hecho de que los crecientes actos de insubordinación esclava después de la segunda mitad de la década de 1870, a menudo se expresaren como un ataque directo al sistema de cuadrillas, estrictamente articulado, en el paisaje, al plantío alineado vertical de los cafetos (Stein, 1990, p. 176; Gomes, 2006, p. 257; Machado, 1987, p. 62; Santos, 2014).

Las soluciones de administración del paisaje analizadas en este artículo colapsaron con el fin de la esclavitud, y de hecho ellas fueron parte crucial de la propia crisis de la institución, así como lo fueron las manifestaciones crecientes de resistencia esclava (Stein, 1990, pp. 253-265). Como señaló Emilia Viotti da Costa (1989, p. 37), la dificultad de los propietarios del Valle de Paraíba para atraer inmigrantes europeos a sus haciendas los habían llevado en los 1880 a aferrarse aún más al trabajo esclavo, y una de las razones centrales para la incapacidad de enganchar los trabajadores libres extranjeros era exactamente la disminución de la productividad de sus cafetales, lo que quiere decir la degradación ambiental causada por la tala constante de los bosques mediante la plantación alineada vertical y el abandono de los cafetales viejos. En otros términos, lo que antes era condición para la expansión productiva se convirtió en límite.

El fin de la esclavitud trajo, además de la reconfiguración de las relaciones de trabajo con el colapso del sistema de cuadrillas, un profundo cambio en el paisaje agrario. Como hemos visto a lo largo del artículo, el café, un árbol de origen africano, trabajado por esclavos africanos y sus descendientes, llevó a la construcción del Valle de Paraíba como una región histórica. En la última década del siglo XIX, mientras que hacendados y antiguos esclavos, ahora liberados establecían nuevos acuerdos en los sistemas de aparcería y colonato, un tercer vector de africanización del paisaje ganaba impulso en el Valle. Ese vector se hizo presente desde que las primeras plantaciones de café fueron abandonadas a mediados del siglo XIX. El capim-gordura (Melinis multiflora) que invadió las tierras devastadas por el café, llegó precisamente desde el continente africano (Dean, 1996, p. 130). Fragoso (1983, p. 152) señala que "la tierra en la hierba preceden el ganado", es decir, la formación de pastos fue resultado de la devastación del medio ambiente, al no ser una consecuencia de la introducción de la nueva actividad de pastoreo. En definitiva, el ganado fue la estrategia que los antiguos propietarios empleaban para mantener la integridad de sus propiedades y detener la división de sus tierras (Stein, 1990, pp. 304-335; Fragoso, 1983, pp. 109-155). Y, así, imponer una vez más su dominio sobre el paisaje y los hombres. Pero este es un tema a ser examinado en otra ocasión. 


\section{NOTAS}

1 Processo Crime, 1866, Centro de Documentação Histórica da Universidade Severino Sombra, Vassouras, Cartório de 2응́ㄷㅇ, Caixa 467. El episodio ya fue examinado por McCann (1997, pp. 38-42) y Agostini (2002, pp. 44-56), pero en una clave analítica distinta de la que yo empleo.

\section{BIBLIOGRAFÍA}

Ab’Sáber, Aziz Nacib (2003), Os domínios de natureza no Brasil, São Paulo, Ateliê.

Agostini, Camilla (2002) Africanos no cativeiro e a construção de identidades no além-mar. Vale do Paraíba, século XIX. Dissertação de Mestrado, DH/IFCH/Unicamp.

Aguiar, Pe. João Joaquim Ferreira de (1836), Pequena memória sobre a plantação, cultura e colheita do café, Rio de Janeiro, Imprensa Americana de I.P.da Costa.

Alléon-Dulac, J. L. (1800), "Introdução sobre a cultura do café". En: Frei José Mariano da Conceição Velloso, O Fazendeiro do Brazil. Tomo III, "Bebidas Alimentosas" parte I, Café, Lisboa, Oficina de Thadeu Ferreira.

AHR Exchange (2010), "The Question of 'Black Rice'," The American Historical Review, 115 (1), February, pp. 123-171.

Caldeira, Antonio da Silveira (1843), Memória sobre um novo método de preparar o café. Rio de Janeiro, Typ.Universal de Laemmert.

Campbell, Gwyn (2003), "The Origins and Development of Coffee Production in Réunion and Madagascar, 1711-1972." En: Clarence-Smith, W.G. \& S. Topik (org.), The Global Coffee Economy in Africa, Asia, and Latin América, 1500-1989, Cambridge, University Press.

Carneiro Leão, Honório Hermeto (1957), "Discurso autobiográfico, pronunciado no Senado, na sessão de 31 de julho de 1854," Revista do Instituto Histórico e Geográfico Brasileiro, 236 (3), julho-setembro, pp. 275-284

Carney, Judith A. (2001), Black Rice. The African Origins of Rice Cultivation in the Americas, Cambridge, Mass, Harvard University Press.

Carney, Judith y Robert Voeks (2003), "Landscape legacies of the African diaspora in Brazil," Progress in Human Geography, 27 (2), pp. 139-152.

Carney, Judith y Richard Nicholas Rosomoff (2009), In the Shadow of Slavery. Africa's Botanical Legacy in the Atlantic World, Berkeley, University of California Press.

Costa, Emília Viotti da (1989 [1966]), Da Senzala à Colônia, São Paulo, Brasiliense.

Dean, Warren (1996), A ferro e fogo. A história e a devastação da Mata Atlântica brasileira (trad.port.), São Paulo, Companhia das Letras.
Eltis, David; Philip Morgan y David Richardson (2007), "Agency and Diaspora in Atlantic History: Reassessing the African Contribution to Rice Cultivation in the Americas," American Historical Review, 112 (5), December, pp. 1329-1358.

Florentino, Manolo Garcia (1995), Em Costas Negras. Uma História do Tráfico Atlântico de Escravos entre a África e o Rio de Janeiro (séculos XVIII e XIX). Rio de Janeiro, Arquivo Nacional.

Florentino, Manolo y José Roberto Góes (1995), "Parentesco e família entre os escravos de Vallim." En: Castro, Hebe Maria Mattos de e Eduardo Schnoor (org.), Resgate. Uma janela para o oitocentos, Rio de Janeiro, Topbooks.

Fragoso, João Luis Ribeiro (1983), Sistemas agrários em Paraíba do Sul (1850-1920), Dissertação de Mestrado. Rio de Janeiro: IFCH/ UFRJ.

Fragoso, João Luis Ribeiro (2013), Barões do café e sistema agrário escravista. Paraíba do Sul / Rio de Janeiro (1830-1888), Rio de Janeiro, 7 Letras.

Fragoso, João Luis y Ana Maria Lugão Rios (1995), “Um empresário brasileiro do oitocentos". En: Castro, Hebe Maria Mattos de e Eduardo Schnoor (org.) Resgate. Uma janela para o Oitocentos, Rio de Janeiro, Topbooks.

García, Gloria (2004) "Vertebrando la resistencia: la lucha de los negros contra el sistema esclavista, 1790-1845". En: GonzálezRipoll, M.D.; Consuelo Naranjo, Ada Ferrer, Gloria García y Josef Opatrny, El rumor de Haití en Cuba: Temor, raza y rebeldía, Madrid, Consejo Superior de Investigaciones Científicas.

Geggus, David P. (1993), "Sugar and Coffee Cultivation in Saint Domingue and the Shaping of the Slave Labor Force." En: Berlin, I. \& P. Morgan (org.), Cultivation and Culture. Labor and the Shaping of Slave Life in the Americas, Charlottesville, Va., University Press of Virginia.

Gomes, Flávio dos Santos (2006), Histórias de quilombolas. Mocambos e comunidades de senzalas no Rio de Janeiro, século $X I X$, (Edição revista e ampliada), São Paulo, Companhia das Letras.

Gorender, Jacob (1985 [1978]) O escravismo colonial, São Paulo, Ática.

Guimarães, Elione (2009), Terra de Preto. Usos e ocupação da terra por escravos e libertos (Vale do Paraíba mineiro, 1850-1920), Niterói, Ed. UFF. 
Higman. B.W. (2001), Jamaica Surveyed. Plantation Maps and Plans of the Eighteenth and Nineteenth Centuries, Kingston, University of the West Indies Press.

"Instruções geraes para a administração das fazendas (23 de fevereiro de 1870)" (2000), En: Araújo, E. (org.) Negro de corpo e alma. Mostra do Redescobrimento. Brasil 500 anos, São Paulo, Fundação Bienal.

Kaye, Harvey J. (1990), "E.P. Thompson, the British Marxist Historical Tradition and the Contemporary Crisis." En: Kaye, $\mathrm{H}$. \& K. McClelland (org.), E.P. Thompson. Critical Perspectives, Philadelphia, Temple University Press.

Laborie, P.J. (1800), “Cultura do Café. Plantador de café de São Domingos". En: Frei José Mariano da Conceição Velloso, $O$ Fazendeiro do Brazil, Tomo III, "Bebidas Alimentosas", parte II, Café, Lisboa, Oficina de Thadeu Ferreira.

Laërne, C.F.van Delden. (1885), Brazil and Java. Report on CoffeeCulture in America, Asia, and Africa, Londres-Haia, Martinus Nijhoff.

Machado, Maria Helena P.T. (1987), Crime e escravidão. Trabalho, luta e resistência nas lavouras paulistas, 1830-1888, São Paulo, Brasiliense.

Maria Rodrigo, Vicente y Pablo Boloix (1817), "Informe de la comisión nombrada por la Real Sociedad, para examinar un escrito anônimo, sobre un nuevo método para el cultivo y beneficio del café", Memorias de la Real Sociedad Económica de la Habana, Número 5, maio.

Marquese, Rafael de Bivar (1999), Administração \& Escravidão. Idéias sobre a gestão da agricultura escravista brasileira, São Paulo, Hucitec.

Marquese, Rafael de Bivar (2005), "Moradia escrava na era do tráfico ilegal: senzalas rurais no Brasil e em Cuba no século XIX", Anais do Museu Paulista. História e Cultura Material, Nova Série. 13 (2), pp. 165-188, jul.-dez.

Marquese, Rafael de Bivar (2006), "Revisitando casas-grandes e senzalas: a arquitetura das plantations escravistas americanas no século XIX", Anais do Museu Paulista, 14 (1), pp 11-57, jan.jun.

Marquese, Rafael de Bivar (2009), “A ilustração luso-brasileira e a circulação dos saberes escravistas caribenhos: a montagem da cafeicultura brasileira em perspectiva comparada", História, Ciências, Saúde - Manguinhos, 16 (4), pp. 855-880, out-dez.

Marquese, Rafael y Dale Tomich (2009), "O Vale do Paraíba escravista e a formação do mercado mundial do café no século XIX". En: Salles, R.; Grinberg, K. (org.) O Brasil Imperial. Volume 2 (1831-1871), Rio de Janeiro, Civilização Brasileira.

Marquese, Rafael de Bivar (2010), "O Vale do Paraíba cafeeiro e o regime visual da segunda escravidão: o caso da fazenda Resgate", Anais do Museu Paulista, 18 (1), 83-128, jan-jun.

Matiello, José Braz (1991), o Café. Do cultivo ao consumo, São Paulo, Globo.
Mattos, Ilmar Rohloff de (1987), O tempo saquarema. A formação do Estado Imperial, São Paulo, INL/Hucitec.

McCann, Bryan Daniel (1997), "The Whip and the Watch: Overseers in the Paraíba Valley, Brazil", Slavery and Abolition, 18 (2), pp. 30-47.

Mitchell, Don (1996), The Lie of the Land. Migrant Workers and the California Landscape, Minneapolis, The University of Minnesota Press.

Moore, Jason (2011), "Transcending the metabolic rift: a theory of crises in the capitalist world-ecology", The Journal of Peasant Studies, 38 (1), pp. 1-46.

Morgan, Philip (1988) "Task and Gang Systems. The organization of labor on New World plantations". En: P.Innes (org.), Work and labor in early America, Chapel Hill, The University of North Carolina Press.

Moreno, Breno Aparecido Servidone (2013) Demografia e trabalho escravo nas propriedades rurais cafeeiras de Bananal, 18301860, Dissertação de Mestrado em História Social. FFLCH/USP, São Paulo.

Moura, Carlos Eugênio Marcondes de (2002 [1976]), O Visconde de Guaratinguetá. Um fazendeiro de café no Vale do Paraíba, São Paulo, Studio Nobel.

Muniz, Célia Maria Loureiro (1979), Os donos da terra. Um estudo sobre a estrutura fundiária do Vale do Paraíba Fluminense, século XIX, Dissertação de Mestrado. Niterói, ICHF/UFF.

Noda, Tranquilino Sandalio de (1830), "Memoria publicada por la Real Sociedad Patriotica sobre esta cuestión del programa: 'Cuáles son las causas a que puede atribuirse la decadencia del precio del café, y si en las actuales circunstancias de su abatimiento seria perjudicial empreender su cultivo, o prudente abandonarlo'. Programa publicado en el Diário del Gobierno de la Habana en 10 de abril de 1829". En: Actas de las Juntas Generales que celebro la Real Sociedad Económica de Amigos del País de la Habana, en los dias 14, 15 y 16 de diciembre de 1829, Havana, Imprenta del Gobierno.

Parron, Tâmis Peixoto (2011), A política do tráfico negreiro no Império do Brasil, 1826 a 1850, Rio de Janeiro, Civilização Brasileira.

Ribas, Rogério de Oliveira (1989), Tropeirismo e escravidão: um estudo das tropas de café das lavouras de Vassouras, 18401888, Dissertação de Mestrado em História. Curitiba, UFPR.

Saint-Hilaire, Auguste de (1974), Segunda Viagem do Rio de Janeiro a Minas Gerais e a São Paulo (1822), (trad. port.) São Paulo, Edusp - Belo Horizonte, Itatiaia.

Salles, Ricardo (2008), E o Vale era o Escravo. Vassouras, século XIX - Senhores e escravos no coração do Império, Rio de Janeiro, Civilização Brasileira.

Santos, Marco Aurélio dos (2014), Geografia da escravidão na crise do Império: Bananal, 1850-1888, Tese de Doutorado em História Social. FFLCH/USP, São Paulo. 
Silva, Eduardo (1984), Barões e Escravidão. Três gerações de fazendeiros e a crise da estrutura escravista, Rio de Janeiro, Nova Fronteira.

Slenes, Robert W (1986), "Grandeza ou Decadência? O mercado de escravos e a economia cafeeira da Província do Rio de Janeiro, 1850-1888", in: I. del Nero (org.), Brasil: história econômica e demográfica, São Paulo: IPE-USP.

Slenes, Robert W (2000)“'Malungo, ngoma vem!' África coberta e descoberta no Brasil”. En: Araújo, E. (org.) Negro de corpo e alma. Mostra do Redescobrimento. Brasil 500 anos, São Paulo, Fundação Bienal de São Paulo.

Stein, Stanley J. (1990 [1957]), Vassouras. Um município brasileiro do café, 1850-1900, Rio de Janeiro, Nova Fronteira.

Taunay, Affonso (1939), História do Café no Brasil, 15 v., Rio de Janeiro, DNC.
Taunay, Carlos Augusto (2001 [1839]), Manual do Agricultor Brasileiro, Rafael de Bivar Marquese (org.), São Paulo, Companhia das Letras.

Tschudi, J.J. (1980 [1866]), Viagem às Províncias do Rio de Janeiro e São Paulo. São Paulo, Edusp - Belo Horizonte, Itatiaia.

Tuchscherer, Michel (2003), "Coffee in the Red Sea Area from the Sixteenth to the Nineteenth Century". En: W.G.Clarence-Smith \& S.Topik (org.), The Global Coffee Economy in Africa, Asia, and Latin América, 1500-1989, Cambridge, Cambridge University Press.

Werneck, Francisco Peixoto de Lacerda (barão de Pati do Alferes) (1985 [1847]). Memória sobre a Fundação de uma Fazenda na Província do Rio de Janeiro, Eduardo Silva (org.). Rio de Janeiro, Fundação Casa de Rui Barbosa/ Brasília, Senado Federal.

Youssef, Alain el (2010), Imprensa e escravidão: política e tráfico negreiro no Império do Brasil (Rio de Janeiro, 1822-1850), Dissertação de Mestrado em História Social. FFLCH/USP, São Paulo. 